\title{
Analysis of Interactive Solar Energy Web Maps for Urban Energy Sustainability
}

Maps and geographic information systems (GIS) bave become vital tools for decision-making, communication, and outreach in the domain of urban energy sustainability. One emerging example involves interactive online maps that allow users to assess rooftop solar energy potential on a building of interest. These maps are interesting in two ways: they are new forms of technology in and of themselves, and they have only become relevant with the changes in renewable energy technologies that allow individuals to participate in this new economy of energy production. The purpose of this study is to describe and analyze the cartographic representation and functionality of urban-scale solar energy maps in the United States. Using competitive analysis, we assess twelve interactive online maps to understand their: (1) design, (2) usage of visual variables and interaction operators, and (3) content, purpose, and goals. Across these three types of assessment, we find both a wide variety as well as some consistent themes. Our results also show that some maps followed cartographic conventions (Brewer 2016; Slocum et al. 2009) while others did not. Through our analysis we develop a set of best practices that can be used to improve the effectiveness and widen the functionality of online solar energy maps. In particular, we make recommendations on how to develop future online, interactive renewable energy maps in a way that keeps the end user in mind while communicating relevant information to a broader range of stakeholders involved in urban energy sustainability (homeowners, utility operators, city officials, and urban planners).

KEYWORDS: web maps; urban planning; solar energy; content analysis; competitive analysis

\section{INTRODUCTION}

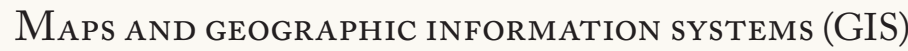
have become vital decision-making, communication, and outreach tools for local decision-makers. Advancements in interactivity and data sharing have improved their ability to generate and disseminate knowledge. An emerging application domain for maps and GIS is energy sustainability planning, which has two broad dimensions. One involves mapping the types and quantity of urban energy consumption to target energy efficiency investments and policy efforts (Webster et al. 2013). The second involves mapping renewable energy potential to identify and manage issues related to new forms of energy generation (Calvert et al. 2013; Resch et al. 2014). The former dimension is familiar to urban stakeholders, while the latter is a new domain to them; only recently have renewable energy technologies advanced sufficiently that these stakeholders can now participate directly in energy production. Energy sustainability planning web maps need to be designed for a public audience but provide complex information and calculations to their users.

Advancements to photovoltaic (PV) technologies are re-configuring stakeholder relations and bringing new social and technical challenges and opportunities to cities. Prospective developers now search within cities for PV electricity generation opportunities located near demand centers. Initially due to government incentives and now due to falling costs, homeowners find the PV business case to be compelling and are interested in becoming electricity producers as well as consumers (so-called "prosumers"). Both of these groups are primarily interested in site-specific production potential and the economic performance 
of PV systems, called solar potential. Solar potential is defined as the amount of solar energy that reaches a surface over a defined time interval influenced by terrain, shadows, and atmospheric factors on a surface (called solar irradiance), limited by the efficiency of the technology available to convert it into usable energy (Angelis-Dimakis et al. 2011). As these technologies become easier to install, utilities, willingly or not, need to adapt their infrastructure and operation practices to accommodate these new forms and sites of generation; they are interested in where new generation is likely to emerge and how power flows through the city will be affected. At the same time, urban planners must consider potential zoning issues to manage system siting and access to solar resources. City officials, meanwhile, have the responsibility of ensuring that PV development does not exacerbate, and perhaps even helps to improve, existing issues within the city such as poverty, environmental injustice, and cultural heritage.

Interactive web maps have the potential to facilitate and perhaps coordinate informed decisions within and between these stakeholder groups. Indeed, urban-scale energy resource mapping has become increasingly common, marked by the rise in online energy maps in cities across the world (see Kanters et al. 2014), as well as through growing literature on the subject (e.g., Calvert et al. 2013; Resch et al. 2014; Freitas et al. 2015). Studying best practices in terms of map design and functionality is critical to improving the decision-making and outreach capacity of these tools and, in turn, to providing urban stakeholders with the tools they require to facilitate the transition to renewable energy in a rapid and responsible way.

The purpose of this study is to describe and analyze the cartographic representation and functionality of available solar energy web maps developed by and for cities within the United States. We have two main objectives: first to add to the literature on cartographic design, representation, and interactivity of publicly available interactive maps using competitive analysis; second, to contribute to the literature and practice of energy geography and planning through benchmarking the development and use of geospatial technologies in urban-scale $\mathrm{PV}$ production. Our results are based on an analysis conducted in June 2016. We conclude by identifying "best practices" from which to establish guidelines and future areas of research that might improve the development of urban energy maps.

\section{BACKGROUND}

Generally speaking, research in energy mapping has focused on the development of spatial decision support system (SDSS) tools (e.g., Calvert et al. 2013; Resch et al. 2014) at the expense of studying the tools themselves. This is especially the case for urban solar energy. The most recent review of SDSS development by Freitas et al. (2015) examines the data and models used to develop urban-scale solar energy maps. Although critical to building effective maps, they do not focus on cartographic representation or functionality for the user. Kanters et al. (2014) provide the only review of front-end components of solar energy web maps, comparing them in terms of content displayed to the user: for example, the range of solar energy technologies considered by each map, or the land-use and land-cover categories used to limit the location of solar PV systems. In these studies, maps were assessed from an engineering and economic perspective. There is need to expand on these analytical approaches, and to evaluate the capacity of online solar energy maps to facilitate informed decisions by also taking into account how the tools make information available to the end user.
One method to achieve this is competitive analysis, which is often used to evaluate currently available software, hardware, or web products to inform future designs and to identify best practices. A competitive analysis is designed to be the first step in understanding services across a range of products. The results of this type of analysis can provide "ad hoc guidelines for approaches that seem to work and others that should be avoided" (Nielsen 1992, 14). Within cartography, Roth et al. (2015) used this method to evaluate currently available web maps for assessing sea and lake level differences, with the goal of examining best practices to create a map of their own.

This study also draws on content analysis, a systematic approach used to examine and compare modes and symbols of communication (Rose 2012). Content analysis relies on identifying a set of codes (Krippendorff 2013). These codes offer a systematic lens through which to examine a common set of themes. Ideally, once the codes are determined, anyone trained in the coding scheme will be able to assess the same sample set or apply the codes to a new sample 
(Muehlenhaus 2010). Content analysis, however, does not allow the analyst to understand why the map was designed in a particular way or how a map reader cognitively encodes the information presented (Lutz and Collins 1993).

Content analysis has become a popular method in cartographic research, beginning with Edsall (2007), who used it to evaluate "maps in the wild" that had impacts on political discourse in the United States. He was followed by Muehlenhaus (2013), who used content analysis to evaluate the propagandist nature of political maps. Additionally, Muehlenhaus identified the appropriate use of visual variables, widely viewed as the building blocks of cartography, across his sample (Bertin 1983; MacEachren
1995). Kessler and Slocum (2011) were the first to use content analysis to compare cartographic design. They evaluated how design has changed and whether map design improved during the $20^{\text {th }}$ century. The codes used in their study were derived from cartographic guidelines outlined in Slocum et al. (2009). Their analysis evaluated cartographic representation elements including: the title, legend, projection used, visual hierarchy, symbology, lettering, basemap, inset maps, and scale. Our study used competitive analysis and is informed by past studies using content analysis. It not only describes the similarities and differences across different maps (i.e., benchmarking), but extracts best practices that should be considered for future map designs (i.e., establishing guidelines).

\section{METHODS}

This study APPLIEs competitive analysis in order to achieve three main goals:

1. evaluate the design of interactive online solar energy maps;

2. assess the usage of their visual variables and map interaction operators; and

3. analyze the content, purpose, and goals of each map related to facilitating planning of potential rooftop solar projects.

We assessed the design of cartographic representation and map interaction in twelve interactive solar energy web maps (Table 1). Maps were included in the sample if they illustrated installed solar energy systems and/or allowed an individual to calculate solar energy potential. All of the maps were large-scale maps of urban or suburban locations in the United States. Additionally, all of the maps assessed in this study are web maps (e.g., not a static map such as an image). Three of the maps were developed in the now-outdated ActionScript for Flash developed by Adobe. The other nine were developed in JavaScript.

Of the twelve maps, two had the same design for multiple locations: Google Project Sunroof and Mapdwell Solar System. In these cases, the same design template was applied to multiple cities. We grouped these maps according to their developer, and assessed only one location each. The other ten maps were all designed for specific locales. Six of the maps were designed by Critigen. These were not considered to be one map as in the case of Google and
Mapdwell, since Critigen's designs varied widely between cities. The remaining four maps were developed by local governments or local nonprofits.

Five groups of codes were developed for this study to assess: (1) map design, (2) use of visual variables, (3) use of map interaction operators, (4) the capability to allow a user to assess the solar potential of a particular building, such as

\begin{tabular}{ll} 
Map Name & Developer \\
Google Project Sunroof & Google \\
Green Riverside & City of Riverside \\
LA County Solar Map & Critigen \\
MadiSUN Solar Energy Map & Critigen \\
Mapdwell Solar System & Mapdwell \\
Metro Orlando Solar Map & Critigen \\
New Orleans Solar Calculator & Critigen \\
New York City Solar Map & Sustainable CUNY \\
Salt Lake Solar Map & Salt Lake City \\
San Diego Solar Map & Critigen \\
San Francisco Energy Map & Critigen \\
Tallahassee Interactive Solar Map & City of Tallahassee \\
\hline
\end{tabular}


their own home, and (5) ability to view information about currently installed systems. With the exception of the first code group (map design), which used a Likert scale to rate design quality, these codes were primarily qualitative and assessed the presence or absence of a particular visual variable, map interaction operator, or capability. Code groupings 1 and 2 enabled an assessment of maps according to cartographic principles, while code groupings 3-5 enabled an assessment of the efficacy of the tools to facilitate and coordinate informed planning decisions within and between urban stakeholder groups.

Two independent coders trained in the coding scheme assessed each map based on the first three code groups. Before coding, they discussed the codes, and agreed on code definitions based on the cartographic literature. Code groups 4 and 5 were assessed by a single coder. Only one coder was necessary here because these were simple assessments of the presence and absence of content afforded to the user and did not require any triangulation of interpretation.

\section{MAP DESIGN}

To assess the adherence of the maps to cartographic principles, we began with the codes outlined by Kessler and Slocum (2011) and updated them for the purpose of this study. Because their study focused on static maps, while ours focused on interactive maps, some codes were removed while others were added. The codes for evaluating the design of the maps are shown in Table 2. Because the

VISUAL VARIABLES

Quantitative

Size
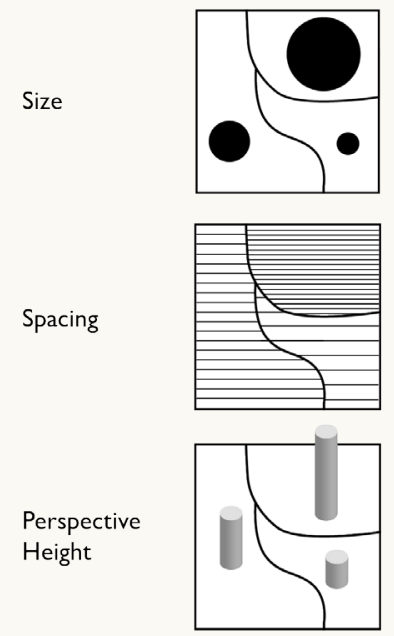

Hue

(Quantitative)

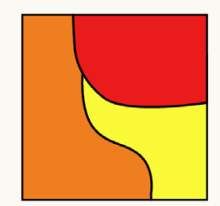

Lightness

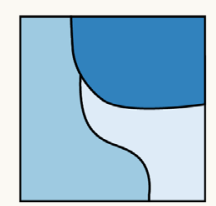

Saturation

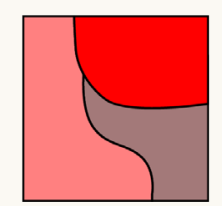

Figure 1. The visual variables (based on Slocum et al. 2009).
Qualitative

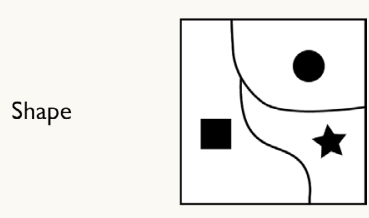

Hue (Qualitative)

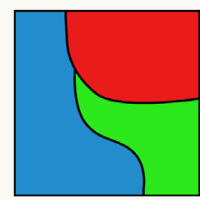

Orientation

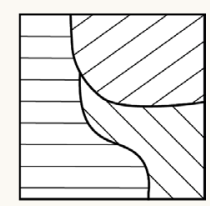

Arrangement

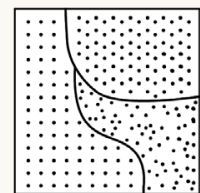
Code
Explanation
Symbology Design
Logical design decisions were made (e.g., a logical progression of colors was used).
Visual Hierarchy
The map has suitable visual hierarchy. Is thematic information emphasized over basemap information? Is there a suitable hierarchy for marginalia elements?
Symbology Coordinates
with Basemap
Does the thematic information coordinate with the basemap in terms of color harmony and readability?
Readability
Is the lettering and other text readable?
Legend Design
Is the legend clear? Does the legend account for all of the symbology on the map?
Splash Page
Is the splash page useful and aesthetically pleasing?
Tutorial
Is there a tutorial? Is it useful? Is it aesthetically pleasing?
Pop-ups/Sidebar
If there are popups or a sidebar, are they useful and well designed?

Table 2. Codes for design assessment. 
codes were applied using a nine-value Likert scale, the scores from the two coders were averaged into a single assessment. The two coders were both trained in cartographic design principles (e.g., Brewer 2016; Slocum et al. 2009) and assigned codes based on Kessler and Slocum's (2011) similar study. Some of the codes allowed "not applicable" as a potential code when a particular element was not present in the maps. Applying a code of "not applicable" was based on unanimous agreement among the coders.

\section{VISUAL VARIABLES}

The visual variables, first described by Bertin (1983), are seen as the building blocks of cartographic representation. There are nine widely accepted visual variables. The variables of hue, saturation, and lightness all are color variables, while the other six variables are: size, shape, spacing, orientation, arrangement, and perspective height (Figure 1; Slocum et al. 2009).

The coders independently coded for the use of the visual variables. A variable was coded as being included in the map only if used to depict thematic content (e.g., solar energy potential); if not used, or used only in the basemap, the variable was coded as being excluded. Any differences in the coding of the visual variables were discussed until a consensus agreement was made on the presence or absence of the visual variable.

\section{INTERACTION OPERATORS}

The interaction operators are the counterparts to the visual variables for interactive maps. There are seventeen interaction operators (Table 3; see also Roth 2013). Understanding which operators are consistently used across a specific type of map can illuminate to the cartographer or web designer what types of interactivity are expected by users, and which interactions are useful to developers and designers.

Independently, the coders examined each of the maps, assessing which operators were included in the map or interface design. Following the coding, the coders assessed agreement and discussed differences. Any differences were reevaluated jointly until the coders came to consensus about their usage.

\begin{tabular}{|c|c|}
\hline Code & Explanation \\
\hline Import & Load a dataset into a map \\
\hline Export & $\begin{array}{l}\text { Produce a map for use outside of the } \\
\text { visualization }\end{array}$ \\
\hline Save & $\begin{array}{l}\text { Store the changes a user may have made in } \\
\text { a visualization for later use }\end{array}$ \\
\hline Edit & Alter the data underlying the map \\
\hline Annotate & $\begin{array}{l}\text { Add markings or text to the map or map } \\
\text { interface }\end{array}$ \\
\hline Reexpress & $\begin{array}{l}\text { Change the type of thematic map used to } \\
\text { display the data }\end{array}$ \\
\hline Arrange & $\begin{array}{l}\text { Rearrange the location of the views in a } \\
\text { coordinated view }\end{array}$ \\
\hline Sequence & $\begin{array}{l}\text { Produce maps in sequence, such as small } \\
\text { multiples }\end{array}$ \\
\hline Resymbolize & $\begin{array}{l}\text { Alter symbolization (e.g., change colors, } \\
\text { adjust classification scheme) }\end{array}$ \\
\hline Overlay & $\begin{array}{l}\text { Reorder or toggle layers (similar to a GIS } \\
\text { table of contents) }\end{array}$ \\
\hline Reproject & Change the map projection \\
\hline Pan & Change the center location of the map \\
\hline Zoom & Change the scale or resolution \\
\hline Filter & $\begin{array}{l}\text { Query the map to show only the results from } \\
\text { the query }\end{array}$ \\
\hline Search & $\begin{array}{l}\text { Enter a specific term to identify an answer } \\
\text { (e.g., search for an address in a map) }\end{array}$ \\
\hline Retrieve & $\begin{array}{l}\text { Identify details by clicking or brushing over } \\
\text { contents of a map (e.g., a popup display) }\end{array}$ \\
\hline Calculate & Compute an answer based on an input \\
\hline
\end{tabular}

Table 3. Interaction operators (from Roth 2013).

\section{DECISION-SUPPORT AND SYSTEM ASSESSMENT FUNCTIONALITY}

The maps in this study allowed users to assess solar potential (a planning task), retrieve information about currently installed systems, or both. As such, two sets of codes were 


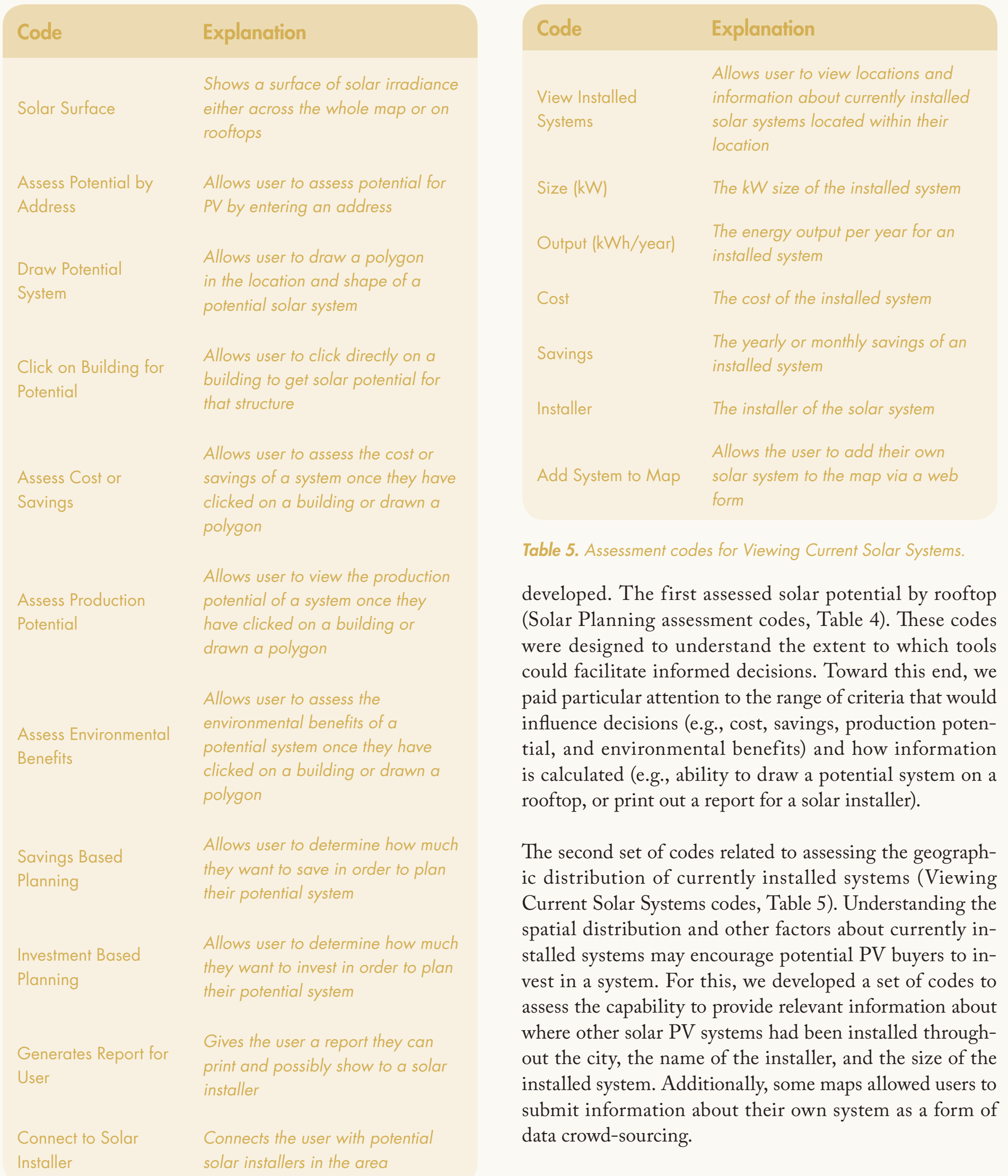

Table 4. Solar Planning assessment codes. 


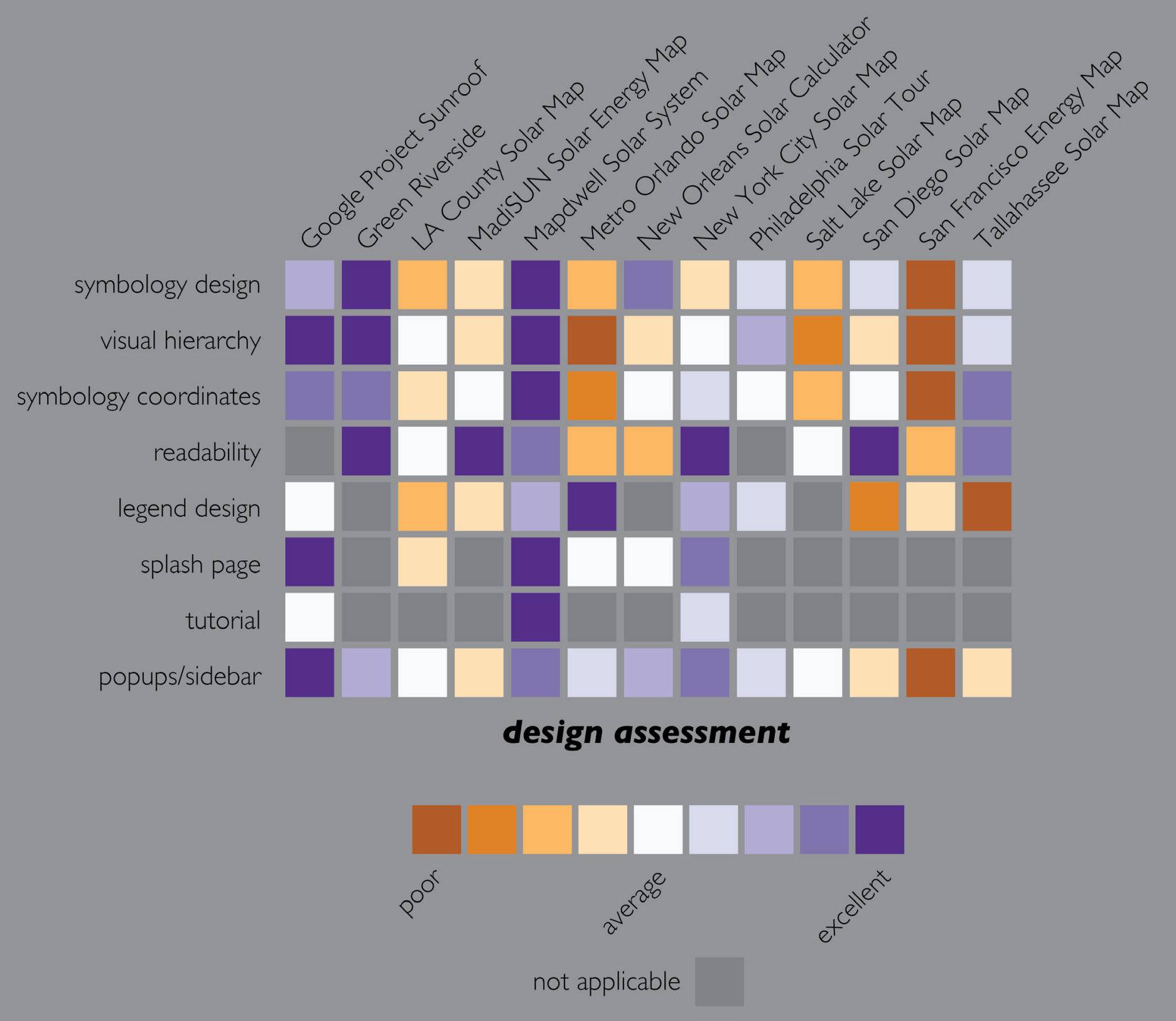

Figure 2. Design code scores.

\section{RESULTS}

\section{MAP DESIGN}

The Design of THE MAPS varied across the sample (Figure 2). Some maps had consistently high scores across the design codes (e.g., Mapdwell Solar System [Figure 3] and Google Project Sunroof), and some scored consistently poorly across the design codes (e.g., San Francisco Solar Energy Map). Ideally a map would perform well across all codes. Many of the maps in the sample had a mix of high and low scores. For example, the Metro Orlando Solar Map scored poorly on the design of the actual map

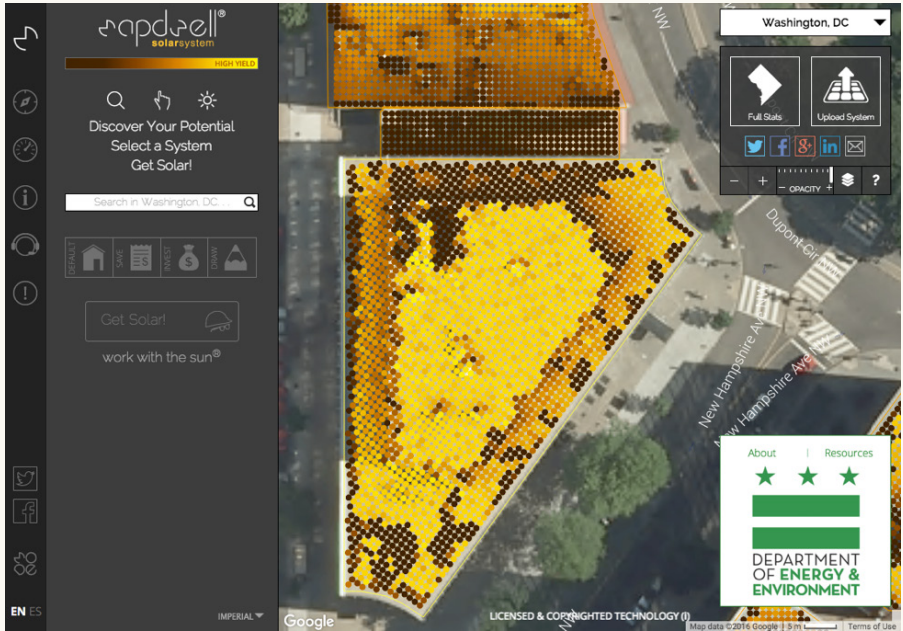

Figure 3. The Mapdwell Solar System scored very well on the design codes. 


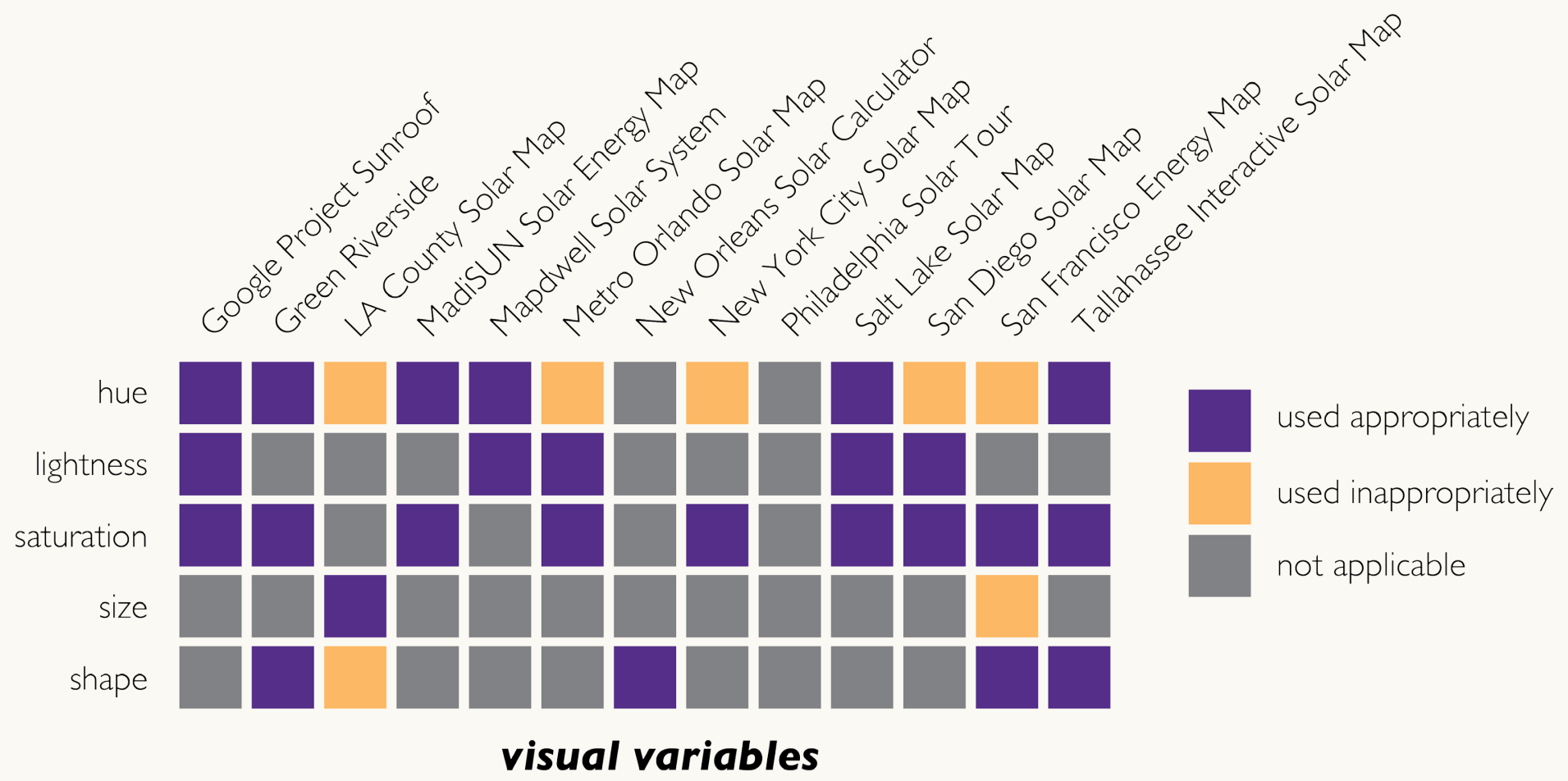

Figure 4. Usage of the visual variables. Several visual variables (spacing, orientation, arrangement, and perspective height) were never used and thus are not shown.

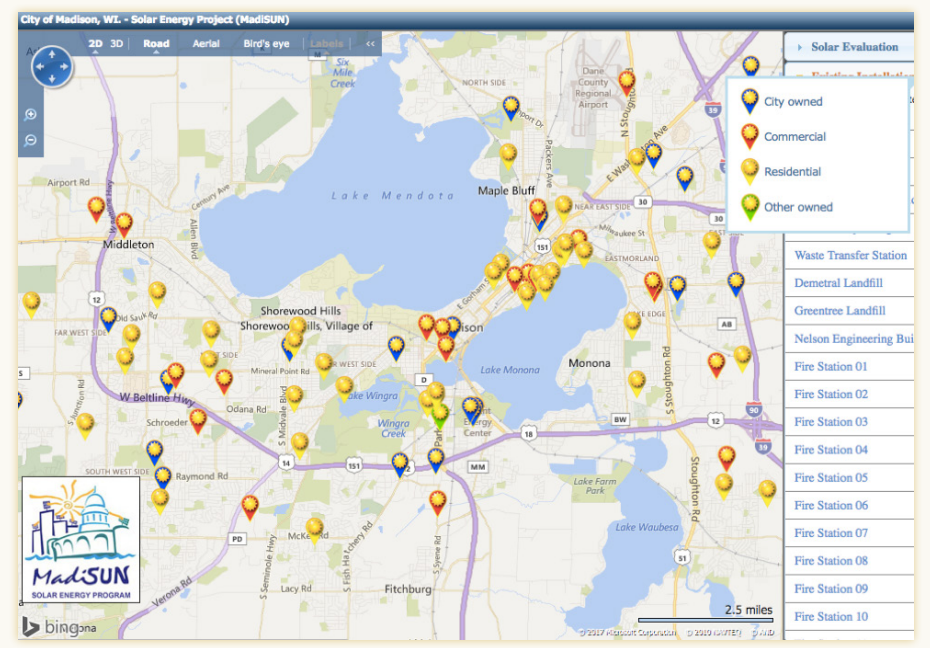

Figure 5. In the MadiSUN map, hue (qualitative) is used to

illustrate differences in the ownership of solar installation projects.

(symbology, visual hierarchy, symbology coordinates with basemap, and readability); however, the legend and other marginalia were well designed.

\section{VISUAL VARIABLES}

Understanding how the visual variables are used in a set of maps helps to identify what elements are necessary or expected in a map (Figure 4). The most commonly used visual variable was hue $(\mathrm{n}=11)$. Hue is useful for illustrating

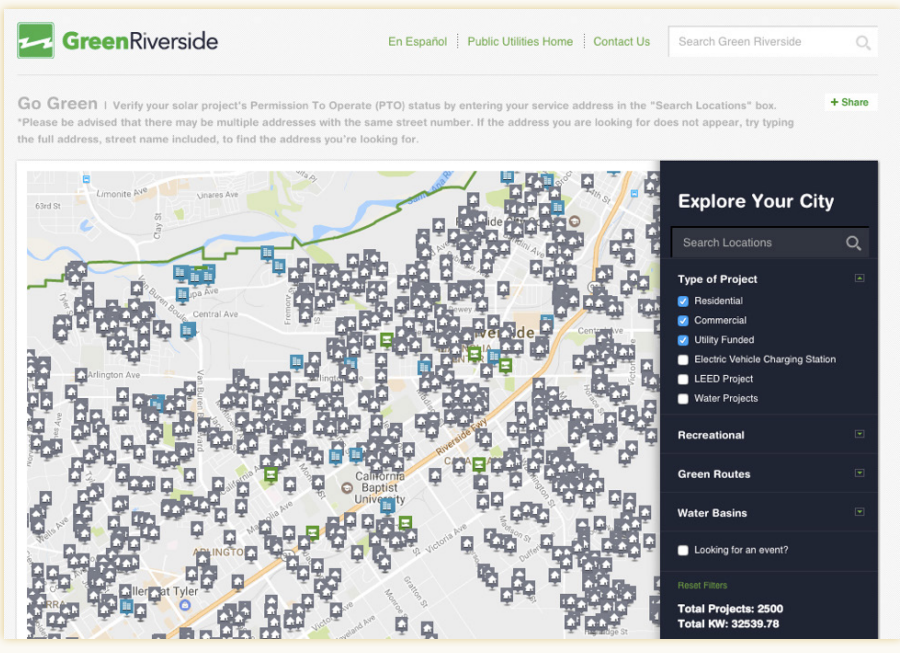

Figure 6. The Green Riverside map uses shape and hue (qualitative) to illustrate the different types of solar installations in the city.

both qualitative and quantitative data; however, when used for quantitative data, it needs to imply order through the colors. Six of the maps used hue appropriately (e.g., Figure 5), while five of the maps did not. When hue was used incorrectly it was through the use of color schemes that did not imply order while illustrating quantitative data (e.g., spectral color schemes or random color choices). Lightness is a quantitative visual variable and was used appropriately in all cases. In some of these cases, it was used in isolation 
and in others it was used with hue to redundantly illustrate differences. Saturation is a difficult visual variable to parse out from the other aspects of color and was only used redundantly with hue or lightness. On five maps, point symbols marking currently installed solar systems used the variable shape to designate different types of installations, sometimes in combination with hue as a redundant visual variable (Figure 6). Two maps used size. Though it is a quantitative visual variable, on the San Francisco Energy Map size was used to illustrate a qualitative difference: types of solar installations. On the LA County Solar Map, size was used in combination with hue as a redundant visual variable to illustrate rooftop solar irradiance. In this case, it was used correctly to show quantitative differences.

\section{INTERACTION OPERATORS}

The results from the assessment of the interaction operators are illustrated in Figure 7. The interaction operators import, pan, and zoom were used in every web map analyzed in this study $(\mathrm{n}=12)$. The search and retrieve operators were each used in all but one of the maps $(n=11)$ : the Tallahassee Interactive Solar Map did not have a search box, and the Salt Lake Solar Map was the only map to not use the retrieve operator (often a mouse-over or click resulting in more information in the form of a pop-up or sidebar).

The export operator was only found in three of the maps in the study, typically generating a downloadable report that the user could bring to a solar installer for more information. Resymbolize, in the form of an opacity change, was used in three of the maps. More than half of the maps allowed for the overlay operator $(n=7)$. In most cases this operator was used to toggle the display of a solar irradiance

\section{interaction operators}
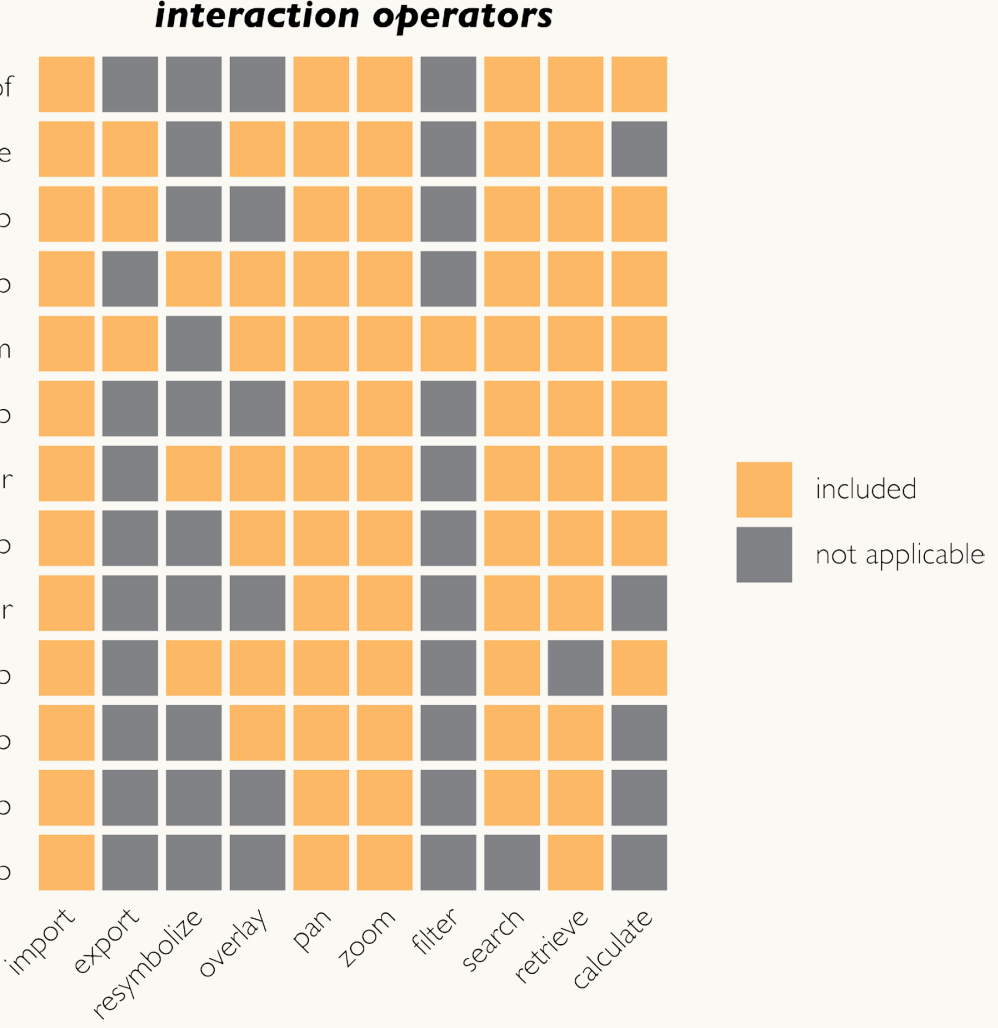

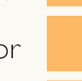
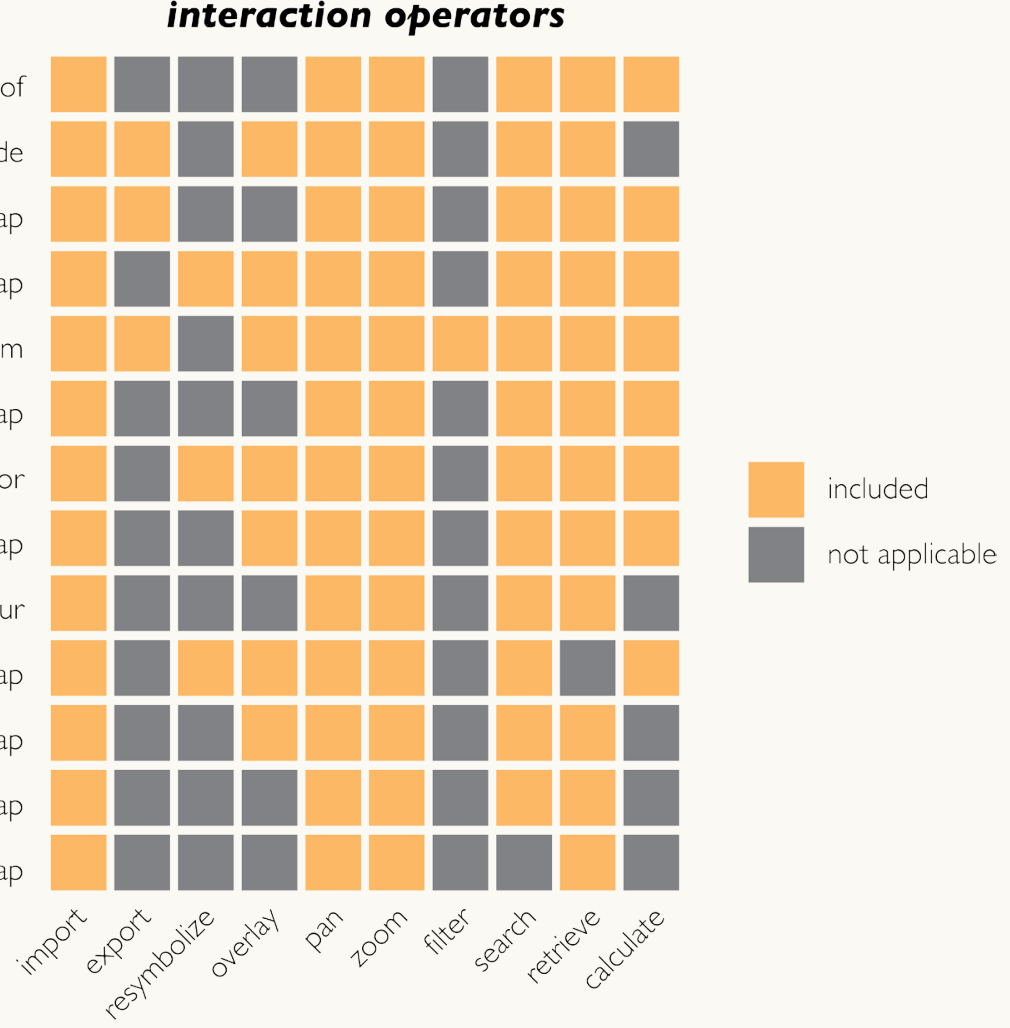

Figure 7. Usage of the interaction operators. Several interaction operators (save, edit, annotate, reexpress, arrange, sequence, and reproject) were never used and thus are not shown.

and reproject) were never used and thus are not shown. w 


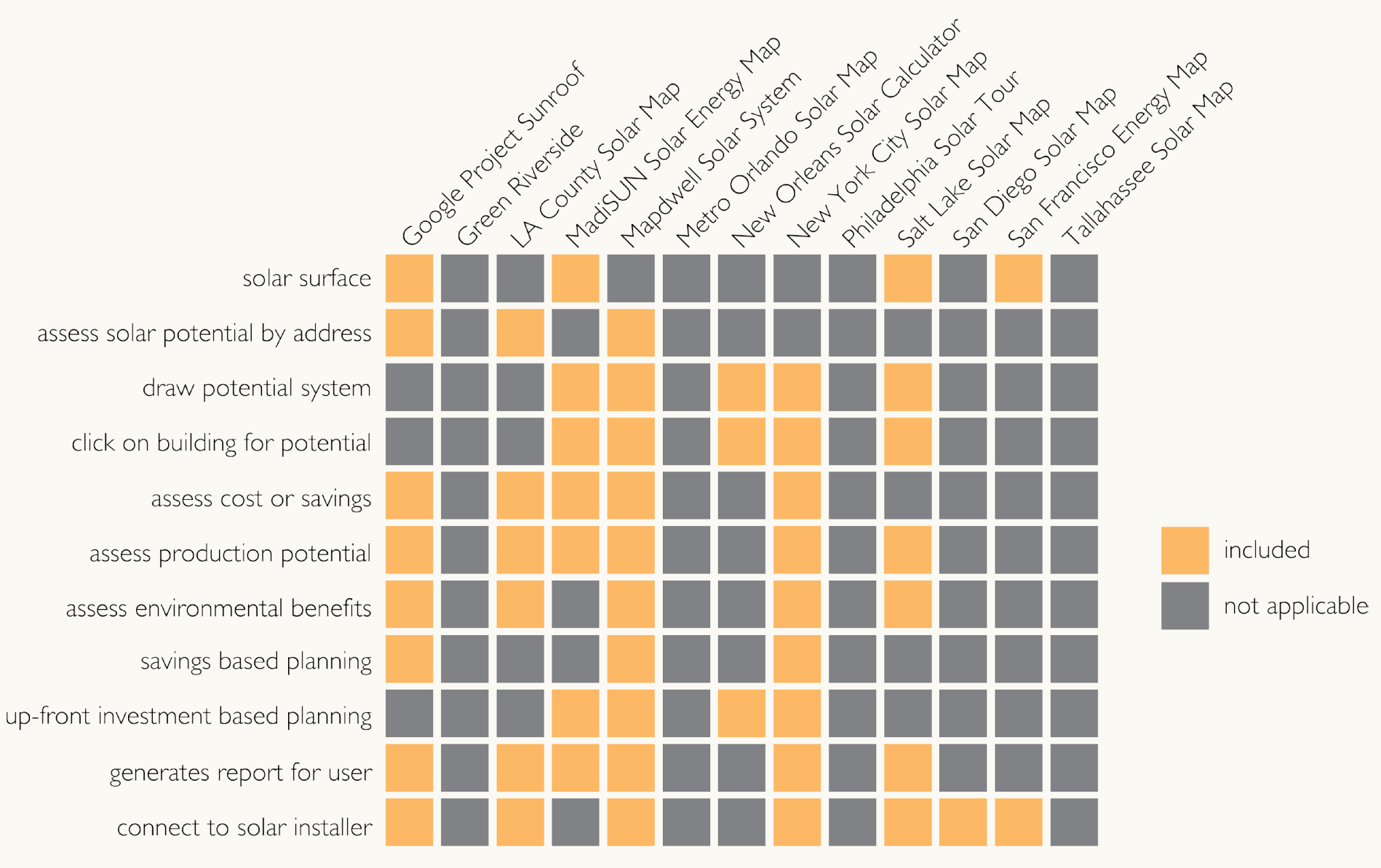

planning for solar

Figure 9. Results of the Planning for Solar assessment. Note that this study did not investigate how irradiance was calculated.

\section{PLANNING FOR SOLAR}

In allowing a user to calculate solar potential on a rooftop, a map may prompt a user to realize the economic and environmental benefits of installing solar PV systems. We analyzed the twelve maps for their capability to allow users to assess solar potential for a rooftop (Figure 9). Across the sample, the maps afforded users several means by which to do so. Four maps provided the user with a surface of solar irradiance (Figure 10). In three maps, the user could assess solar by address by entering an address and receiving a calculated assessment of PV potential. The draw code assessed whether a map afforded the user a tool to draw the ideal size and location for solar PV on a rooftop (Figure 11). This functionality was found in five maps, which then calculated PV potential for the user-drawn polygon. These same five maps also afforded users the option to simply click on a structure and calculate PV potential for an entire roof area.

A number of the maps provided users with potential cost $(\$)$, savings $(\$)$, production $(\mathrm{kW})$, or environmental

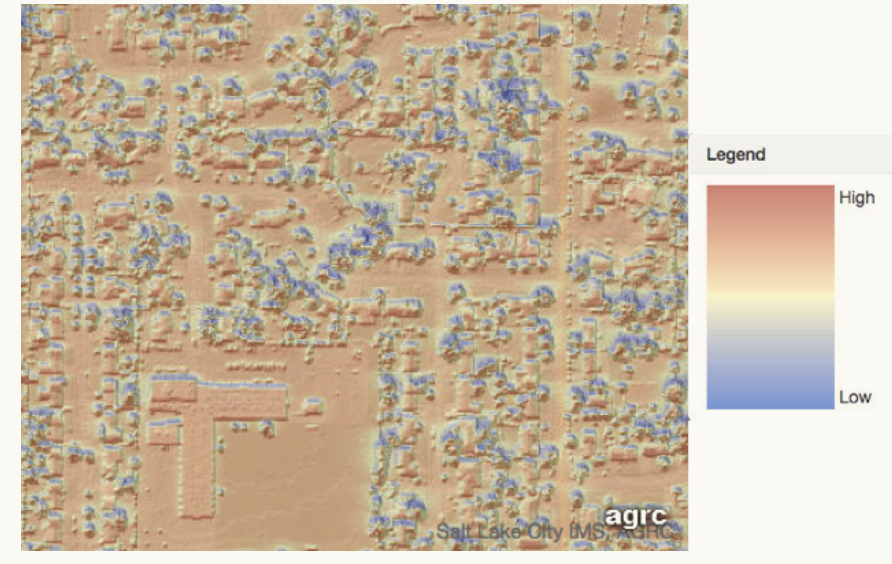

Figure 10. The Salt Lake Solar Map, illustrating the solar irradiance across the entire city.

savings $\left(\mathrm{CO}_{2}\right.$ reductions) after they either searched for an address, clicked on a building, or drew a potential system on a rooftop. Five maps allowed users to assess potential costs and savings of systems they searched for or drew. Six maps 
provided estimates on production potential in $\mathrm{kW}$. This is a useful metric because it does not require the developer to account for the changing prices of energy. Finally, five maps afforded the user the ability to understand the environmental benefits of their potential installation in terms of reduced $\mathrm{CO}_{2}$.

Some maps in the sample were designed to allow the user to input their desired potential savings ( $\mathrm{n}=3$ ), up-front investment $(\mathrm{n}=4)$, or both $(\mathrm{n}=2)$, instead of simply being given information based on their search or drawing. Savingsbased planning allowed users to indicate the amount they wanted to save in order to identify the system size needed, and in some cases (e.g., Mapdwell), the roof location to get them the best "bang for their buck." In the case of tools that focused on up-front investment, users could type in the amount they wanted to spend and the system calculated the size that was possible under that budget constraint. This type of functionality is different than assessments of savings, cost, production, or environmental benefits in that it does not force the user to draw first and assess cost and savings second: users can tell the tool how much they can afford or how much they want to save in order to find out what type of system they might be able to install.

In helping users make the next step towards installation of a rooftop PV system, several tools generate a report to bring to a solar installer or to share with others $(n=6)$, and/or

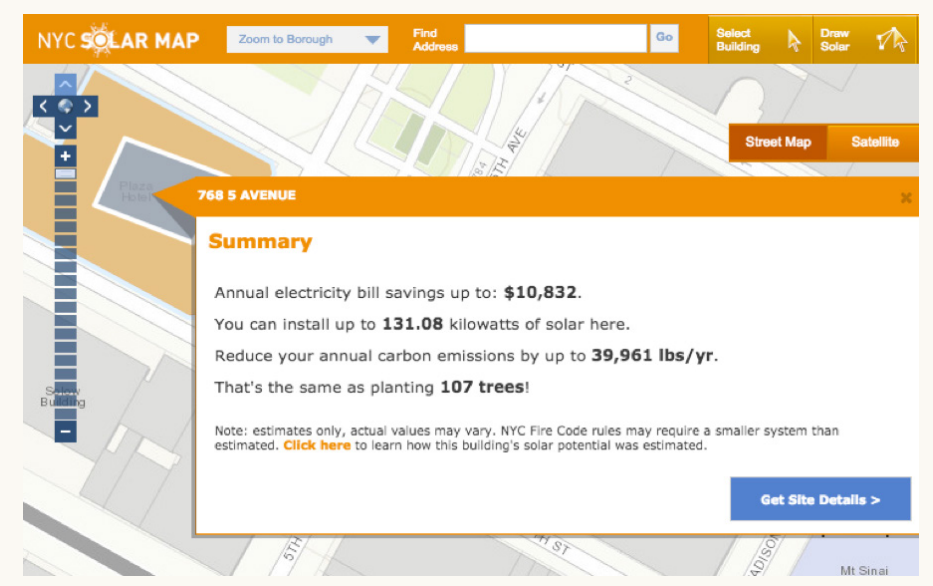

Figure 11. The New York City Solar Map's calculations after drawing a potential system with the draw tool.

connect users to solar installers in their area through hyperlinks located in the web map $(n=7)$.

\section{CURRENT SYSTEMS ASSESSMENT}

The results from the current systems assessment are illustrated in Figure 12. Of the maps in the sample, nine maps provided users with the capability to view currently installed systems in terms of the size of the system in kilowatts (e.g., Figure 13). Significantly fewer of those, only three, provided insight into the total output over the course of the year. Only one map provided the cost (Metro Orlando Solar Map), while one showed the savings (LA County Solar Map) of the installed systems. Several maps $(\mathrm{n}=6)$ provided users with the name of the installer. Since users may want to understand more than simply where currently installed systems are located, cost, savings, and installer may be important factors for potential future prosumers. Finally, five maps provided users the ability to add their own system to the map.

Figure 12. Assessment results for the Viewing Current Solar Systems codes. 


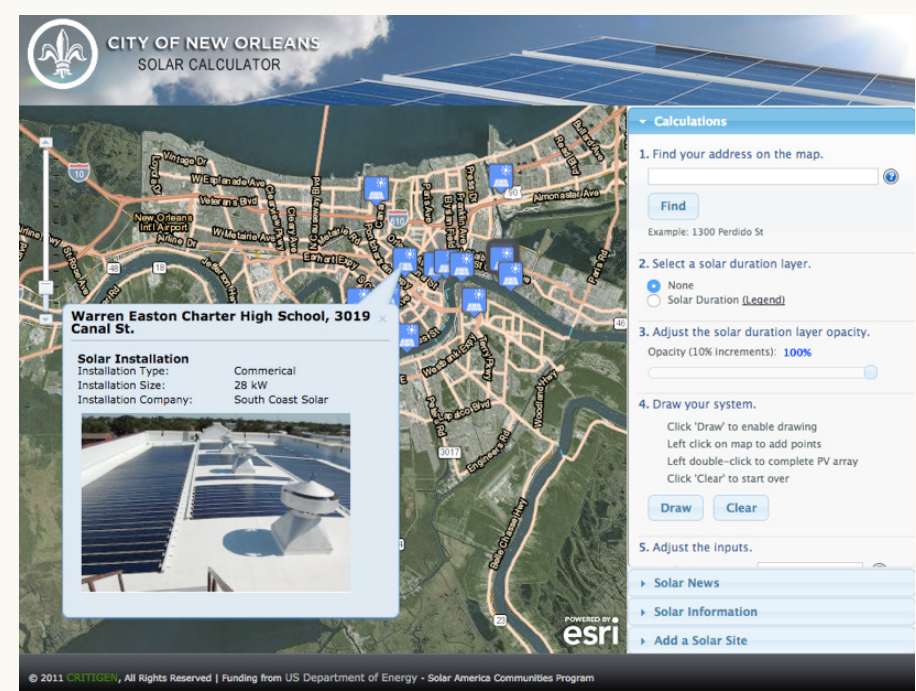

Figure 13. The New Orleans map allows users to explore information. This map also allows users to input parameters to calculate their own solar potential.

The LA County Solar Map scored best on providing users with information about current systems (Figure 14). While

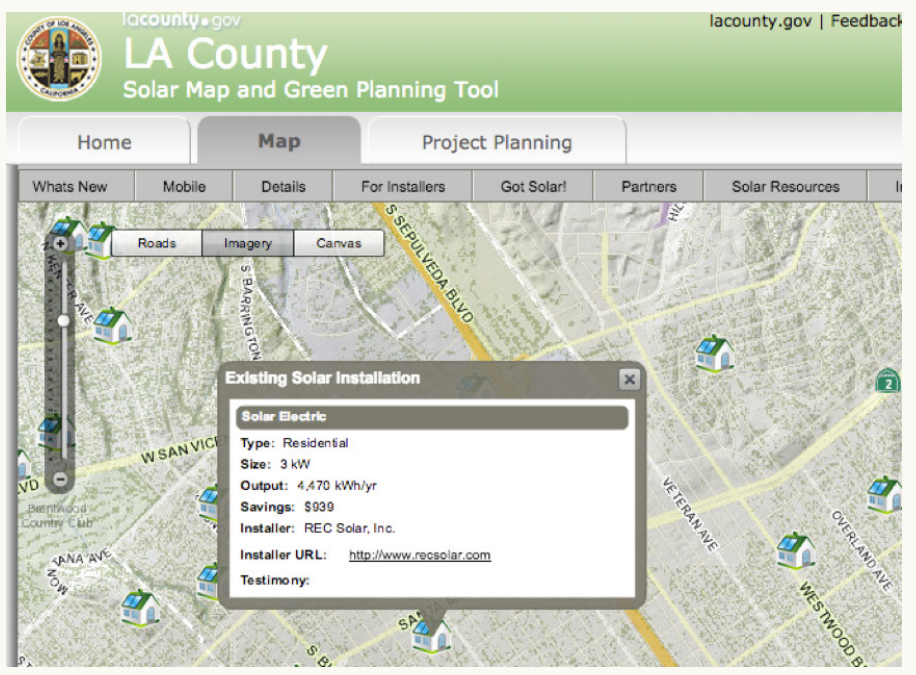

Figure 14. The LA County Solar Map provides users with a large amount of functionality to understand currently installed systems in the area

this map did not score well in the design codes described earlier, it afforded a lot of functionality for its users.

\section{DISCUSSION: BEST PRACTICES}

Solar ENERgy Web MAPS afford users the tools to assess PV potential in a rapid, meaningful way. The results of our analysis suggest that good map design and useful map functionality are not necessarily correlated: maps scoring high on design did not necessarily score high on functionality, and vice versa. Depending on intent of the map, adherence to particular functionality codes differed. Some maps focused on allowing users to calculate electricity production potential, while others focused on providing users a map of currently installed systems. Because both of these functionalities are useful in decision making, it would be helpful for future designs to have both capabilities. After analyzing maps for their adherence to codes, we identified several best practices.

\section{MAP DESIGN}

The codes identified in this research can act as guidelines for future interactive solar energy map designers (Table 2). Specifically, four codes are particularly useful to ensure these maps are well designed. These four codes are: symbology coordinates with basemap, readability, legend design, and design of the popups or sidebar.
Coordinating thematic and basemap layers is difficult. While this is not a new issue in cartography (e.g., Spiess 1970), with easily interchangeable basemaps now available in web maps, this is an aspect of design that cartographers need to consider when developing urban-scale spatial decision support systems. These interchangeable basemaps are often composed of annotated imagery, thus designing thematic layers that coordinate well with the underlying basemap is a primary determinant of design quality. The high level of detail and variety of colors found in imagery make it difficult to design thematic layers that contrast sufficiently. Often, simplified basemaps are suggested instead (Brewer 2016; Spiess 1970); however, in the case of solar energy web maps, imagery provides the resolution required to assess modeled results under real-world conditions (1ocation, weather, etc.). It is also easy to use in common web mapping applications such as Google Maps. Thematic layers composed of highly saturated colors are often best with imagery because they stand out, despite the challenges they may offer designers. The Mapdwell Solar System product does the an excellent job of this, by coordinating highly saturated colors with a consistent color scheme. The San Francisco Energy map, on the other hand, scored poorly in this aspect, as there is little coordination between the visual hierarchy of the map layers, making each 
difficult to discern. How to design the visual hierarchy of maps where thematic layers are salient enough for effective reading (Fabrikant and Goldsberry 2005), without taking away from the visual aesthetics or beauty of the map is an active question in cartographic research (Kent 2005).

Readable text and good legend design are important on both static and interactive maps. Ensuring type is readable across all cases of interaction with a web map is presently a challenge for cartographers (Jenny et al. 2008). Additionally, legends now need to be dynamic and adaptive alongside the interactive map (Sieber et al. 2005), taking into account how layers in the map change as the user interacts with it (Dykes et al. 2010).

Finally, the interactive solar maps examined in this study often included the retrieve operator, which gives the user "details on demand" (Shneiderman 1996) when they click or mouse over areas of the interface or map. Popups and sidebars were well designed when they followed basic design principles (as described in Tufte 1983): visual hierarchy, balance, unity, typography, and color coordination with the rest of the map interface. The best example of this was in the Mapdwell Solar System, which provided users with clear designs adhering to cartographic guidelines (Slocum et al. 2009).

As maps offer more interactivity, cartographers face new challenges in planning for a variety of scales, geographies, and changes that a user might make. In this way, the cartographer has less control over the design. Adherence to underlying data is also a constraint. These maps are scalable and thus planning for every type of geography or change a user makes is challenging. While designing for every case is difficult, it is necessary in these highly interactive web mapping environments. Cartographers might have more success if they limit the capabilities of these web maps by reducing interactivity to avoid having to design for multitudes of use cases (Tufte 1990).

\section{VISUAL VARIABLES}

The maps in this sample used only a subset of the visual variables. Some of the maps used them correctly (e.g., quantitative variable for quantitative information) while other maps did not. Future maps would do well to ensure the correct usage of the visual variables for the type of data displayed. Indeed, the more recently deployed maps in the study (e.g., Mapdwell and Google) used the visual variables more appropriately, suggesting that design and use of visual variables are becoming more important as more of these maps are designed and deployed. In many cases, the variables were also used redundantly for example, using size and color to show areas on a map that had better or worse solar potential. This redundant usage often helps users discern between different features (Retchless and Brewer 2015).

\section{MAP INTERACTION OPERATORS}

Several map interaction operators were widely used in maps of solar energy, including search, retrieve, pan, zoom, import, and calculate. These six operators were found to be more useful in the case of solar energy web maps than the other eleven operators. The search operator afforded users the ability to easily find their home within the map without panning and zooming. This is necessary if the goal is to allow users to assess the energy potential of a particular building. The retrieve operator was likewise important because it allowed the user to query the map for more information. This is necessary for maps that allow users to assess solar potential and information about currently installed solar systems. The pan and zoom operators were found in every solar energy web map analyzed in this study, permitting users to move around the subject area. It is hard to imagine a web map of solar energy potential that does not include these capabilities. Finally, an import operator is automatically executed in every map at loading time as it brings in the pertinent data layers such as a solar irradiance surface or a buildings polygon layer. These systems work best with data already loaded and tailored to the users' specific needs. Unlike a traditional desktop GIS, web maps are most effective in terms of their ability to facilitate informed decisions when their tools, data, and functionality focus on a specific case as opposed to affording the user ultimate control.

\section{SOLAR PLANNING TOOLS}

Maps that allow users to assess solar potential stood out in the sample. The capability to not only view general solar potential in a location, but to calculate solar potential across a specific rooftop may help with decision making and lead to wider implementation of solar energy systems.

Maps that allow users to click on any building to compare solar potential, as opposed to those that required the user to know a specific address, were especially helpful. This 
meant users were able to pan and zoom around the map and assess solar potential for every structure represented on the map. This is useful to a solar energy developer who is interested in identifying clients' buildings with strong solar potential, or a utility system operator interested in identifying rooftops within a specified distance of a node on the electricity grid. Additionally, some of the maps allowed users to draw on a rooftop to assess solar potential for an isolated area of the building. This is useful because it allows a homeowner to assess potential on only the part of the roof where they may want to install a PV system. Future maps could include this functionality not only for rooftops but also for any area seen fit for solar development within the city.

Some maps allowed users to analyze all aspects of system potential (cost, savings, energy production, and environmental benefits). Providing site-specific information about the multiple benefits of solar is important, because prospective investors (homeowners and third-party developers) are increasingly motivated to deploy PV systems based on both economic and environmental benefits. Although these benefits are only a portion of the ultimate PV investment decision (Graziano and Gillingham 2015), they are the perhaps most tangible arguments for installation (Islam and Meade 2013). In addition, for some users, cost will be the most important decision criterion, while for others savings will be the motivating factor.

Another best practice in this grouping was the display of options to connect with an installer. By connecting them directly with a solar installation company or offering a list of companies, map users can more easily realize the economic and environmental benefits of a system at their location of interest. Those maps that allowed the user to print a report might also help in connecting users and installers. If the goal of these maps is to encourage users to think seriously about installing a PV system, providing information about all aspects of system potential, benefits of solar, costs, and solar installation services is ideal for allowing users to make the most informed decision possible.

None of the maps enable a user to calculate potential for multiple rooftops or multiple systems simultaneously; clearly, they were designed to inform homeowners or developers about individual systems. As a means of helping to encourage PV adoption in urban settings, informing homeowners is necessary but by itself insufficient, given that so many other groups have a direct stake in, and influence on, the homeowners' decisions. For a utility operator or policymaker, it is important to be able to retrieve production potential and economic feasibility over wide areas at multiple sites, since the area of interest for these stakeholders is much more extensive. A mapping system that allows a user to identify those areas of the city that may be considered profitable under a specific set of economic conditions (e.g., price of electricity, or tax rebate) would be helpful for utilities and planners to anticipate new development, and help to foster and manage homeowner investment decisions. The combination of multiple different ways to select areas for solar potential calculation is useful. Drawing polygons or selecting a city block can allow community or local government groups to identify undeveloped land for solar, while selecting specific buildings is useful for individuals assessing the potential for solar installation on their own building's rooftop.

\section{CURRENT SYSTEMS ASSESSMENT}

The likelihood of adopting PV technology is influenced not only by favorable characteristics in the built environment, but also by peer effects. All else being equal, the existence of a system installed on a neighbor's roof is a strong determinant in shaping a homeowner's decision to build their own (Graziano and Gillingham 2015). Visibility (i.e., proof that these systems can work in the area) and social interaction (i.e., conversations between neighbors about the benefits and overcoming challenges), not to mention the desire to fit into a new sub-group of early PV adopters are all part of the "peer effect." With this in mind, online solar maps that include information about existing systems (e.g., the LA County Solar Map or the Green Riverside Map) are likely to be more effective than maps that only provide information about a hypothetical system. Thus, the functionality of simply allowing users to view currently installed systems may be sufficient, however additional information about nearby solar installations may also be persuasive. Future research on the effectiveness of these maps with users would benefit from examining what information is most important to users about their neighbors' installed systems. However, providing information such as this opens questions about privacy for homeowners and businesses who have already installed solar PV systems. Finally, the ability for a homeowner to add their currently installed system provides the user with a way to "show-off" their system and may be yet another way to encourage both the installation of solar as well as use of the map (Floreddu and Cabiddu 2012). 


\section{FUTURE DIRECTIONS}

The maps evaluated here provide insight into best practices for future solar energy web maps, based on a systematic coding system. We have identified several additional elements that would be worthwhile to incorporate in future maps.

The maps using JavaScript, and its wide variety of libraries, were all newer, faster, easier to use, more capable, and featured better overall design than Flash applications. JavaScript currently has many advantages, including broad usage, accessibility of code examples, and avoidance of proprietary plug-ins. One disadvantage of JavaScript is the need to test and maintain code against different Internet browsers, as well as keep it up-to-date, to avoid broken map interaction capabilities. Many of the maps in this study were designed by contractors for local governments and thus are not maintained as often as necessary. Future maps would benefit from maintenance, which suggests that cities and other stakeholders would need to provide an operational budget for these tools. Finally, while we did not explicitly evaluate system performance in these tools, future evaluations would benefit from evaluating responsiveness and performance of these types of tools, because users are more likely to continue to use a web application if it performs well (Palmer 2002).

Google and Mapdwell have shown that their systems are scalable. Both groups have developed design and functionality platforms that are now being implemented in several cities. Developing a standardized "plug-and-play" platform is critical to expanding the coverage of these maps. Templates that can be shared with local government officials and other stakeholders provide an easy and quick way to increase the number of locations where users have access to these types of maps (Brewer 2003). Templates can have design choices already made, requiring new developers to simply plug in their own local data for a quickly developed map (Esri 2013).

The online maps in this study illustrate an improvement in the use of cartographic design guidelines in more recently deployed maps (Mapdwell and Google). However, continued adherence to cartographic conventions (e.g., the correct usage of the visual variables) is suggested for better understanding of the mapped information by users. Additionally, the design of the interface is perhaps of equal importance with the design of the map, and requires cartographers and web developers to work together.

Developers of these types of web maps must strike a balance between providing enough functionality to their users in terms of interaction operators, solar planning tools, current systems assessment, and web design.

Finally, the online solar energy maps in this study were designed explicitly for the homeowner: only a single rooftop can be analyzed at any one time, and electricity generation and savings are modeled over an annual timeframe. On the other hand, utility companies and urban planners would benefit from maps with a different suite of functions and outputs. For instance, being able to identify all rooftops that would be profitable under a specific tax rebate might be helpful for a policymaker to determine optimal financial incentives. The capability to model the expected power output from multiple rooftops over shorter timescales might be helpful for the utility company to better understand where they may need to upgrade infrastructure to accommodate future PV systems. Although most of these maps have been designed to raise awareness and provide homeowners with a pre-feasibility analysis, there is great potential to leverage these tools in order to assess the spatial interdependencies between homeowners, policy makers, and utility companies.

That said, designing online systems for multiple user groups is challenging. These maps need to be scalable they cannot be designed for one particular city without the ability to change geography within the interactive map. However, planning and designing for every type of geography or change a user can make is challenging. On the one hand, cartographers might have more success if they limit the capabilities of these web maps by reducing interactivity to avoid having to design for multitudes of use cases (Tufte 1990). On the other hand, in order for these systems to be useful, they need to increase their capabilities. Finding a balance is a key area for future research.

\section{CONCLUSION}

Rooftop PV systems have become popular ways for energy consumers to become energy producers. They offer exciting economic opportunities to individuals and environmental opportunities to society more generally. Unlike 
other types of energy, solar has a particular advantage of being spatially dispersed and micro-scalable, allowing for production of energy in the locations that use it most.

The case of solar energy provides a wealth of mapping opportunities for cartographers and GIScientists. It is not a spatially homogeneous subject; there are limits on where PV systems are viable. Mapping the spatial distribution of solar energy is one opportunity for cartographers, but with the advent of interactive web maps, we are no longer limited to a simple, static representation of solar potential. Indeed, we can provide users with opportunities to explore the map in ways that may influence decision making (MacEachren 1994).

Competitive analysis provided a useful way to understand current capabilities, with the goal of developing best practices for these types of maps (Rose 2012). Based on our analysis, best practices include:

1. adherence to basic cartographic principles;
2. flexibility for the user to model "what if" scenarios, including the ability to delineate their own system, and/or to input specific technical and economic data;

3. sharing information about existing systems; and

4. sharing information about credible solar installers.

Designers of solar energy web maps will find these useful as future guidelines. This is critical at a time when solar web maps are expanding their geographic reach and as the technologies appear to be approaching a dominant model that, according to our analysis, may not be optimal; as of May 2016, Google's Project Sunroof covered more than 43 million households in 42 states (Pyper 2016). Looking forward, there is both a clear opportunity and a need to develop more comprehensive systems, particularly in terms of designing for multiple stakeholder groups rather than just homeowners. This will require careful collaboration between researchers, municipalities, and other stakeholder groups such as utility companies and solar developers.

\section{REFERENCES}

Angelis-Dimakis, Athanasios, Markus Biberacher, Javier Dominguez, Giulia Fiorese, Sabine Gadocha, Edgard Gnansounou, Giorgio Guariso, Avraam Kartalidis, Luis Panichelli, Irene Pinedo, and Michela Robba. 2011. "Methods and Tools to Evaluate the Availability of Renewable Energy Sources." Renerwable and Sustainable Energy Revierws 15 (2): 1182-1200. doi: 10.1016/j.rser.2010.09.049.

Bertin, Jacques. 1983. Semiology of Graphics. Madison, WI: University of Wisconsin Press.

Brewer, Cynthia A. 2003. "A Transition in Improving Maps: The ColorBrewer Example." Cartography and Geographic Information Science 30 (2): 159-62. doi: $10.1559 / 152304003100011126$.

2016. Designing Better Maps: A Guide for GIS Users, $2^{\text {nd }}$ Edition. Redlands, California: Esri Press.

Calvert, Kirby, J. M. Pearce, and Warren E. Mabee. 2013. "Toward Renewable Energy Geo-Information Infrastructures: Applications of GIScience and Remote Sensing That Build Institutional Capacity." Renewable and Sustainable Energy Reviews 18: 416-29. doi: 10.1016/j.rser.2012.10.024.

Dykes, Jason, Jo Wood, and Aidan Slingsby. 2010. "Rethinking Map Legends with Visualization.” IEEE Transactions on Visualization and Computer Graphics, 16 (6): 890-99. doi: 10.1109/TVCG.2010.191.

Edsall, Robert M. 2007. "Iconic Maps in American Political Discourse.” Cartographica 42 (4): 335-347. doi: 10.3138/carto.42.4.335

Esri Inc. 2013. “Fast-Track Your App, Map, and Data Model Creation with ArcGIS Solutions Templates: New ArcGIS Solutions Website Makes It Easy to Find Templates for Your Industry." ArcNews. Accessed January 23, 2016. http://www.esri.com/esri-news/ arcnews/winter1314articles/fast-track-your-appmap-and-data-model-creation-with-arcgis-solutionstemplates. 
Fabrikant, Sara Irina, and Kirk Goldsberry. 2005.

"Thematic Relevance and Perceptual Salience of

Dynamic Geovisualization Displays." Proceedings of the $22^{\text {nd }}$ International Cartographic Conference, A Coruña, Spain. http://www.cartesia.org/geodoc/icc2005/pdf/ oral/TEMA15/Session\%203/SARA\%20IRINA\%20 FABRIKANT.pdf.

Floreddu, Paola Barbara, and Francesca Cabiddu. 2012.

"Public Decisions and Citizen Satisfaction: The

Potential Role of Public Participation Geographic Information Systems." International Journal of Electronic Commerce Studies 3 (1): 121-134.

Freitas, S., C. Catita, P. Redweik, and M. C. Brito. 2015. "Modelling Solar Potential in the Urban Environment: State-of-the-Art Review." Renewable and Sustainable Energy Reviews 41: 915-31. doi: 10.1016/j. rser.2014.08.060.

Graziano, Marcello, and Kenneth Gillingham. 2015. "Spatial Patterns of Solar Photovoltaic System Adoption: The Influence of Neighbors and the Built Environment." Journal of Economic Geography 15 (4): 815-39. doi: 10.1093/jeg/lbu036.

Islam, Towhidul, and Nigel Meade. 2013. "The Impact of Attribute Preferences on Adoption Timing: The Case of Photo-Voltaic (PV) Solar Cells for Household Electricity Generation.” Energy Policy 55: 521-30. doi: 10.1016/j.enpol.2012.12.041.

Jenny, Bernhard, Helen Jenny, and Stefan Räber. 2008. "Map Design for the Internet." In International Perspectives on Maps and the Internet, edited by Michael P. Peterson, 31-48. Berlin \& Heidelberg: Springer. doi: 10.1007/978-3-540-72029-4_3.

Kanters, Jouri, Maria Wall, and Elisabeth Kjellsson. 2014. "The Solar Map as a Knowledge Base for Solar Energy Use." Energy Procedia 48: 1597-1606. doi: 10.1016/j.egypro.2014.02.180.

Kent, Alexander J. 2005. "Aesthetics: A Lost Cause in Cartographic Theory?” The Cartographic Journal 42 (2): 182-88. doi: 10.1179/000870405X61487.
Kessler, Fritz C., and Terry A. Slocum. 2011. "Analysis of Thematic Maps Published in Two Geographical Journals in the Twentieth Century." Annals of the Association of American Geographers 101 (2): 292-317. doi: 10.1080/00045608.2010.544947.

Krippendorff, Klaus. 2013. Content Analysis: An Introduction to Its Methodology. Los Angeles: Sage.

MacEachren, Alan M. 1994. "Visualization in Modern Cartography: Setting the Agenda." In Visualization in Modern Cartography, edited by Alan M.

MacEachren and D. R. Fraser Taylor. doi: 10.1016/ B978-0-08-042415-6.50008-9.

1995. How Maps Work: Representation, Visualization, and Design. New York: The Guilford Press.

Muehlenhaus, Ian. 2010. "Lost in Visualization: Using Quantitative Content Analysis to Identify, Measure, and Categorize Political Cartographic Manipulations." $\mathrm{PhD}$ diss., University of Minnesota.

_. 2013. "The Design and Composition of Persuasive Maps." Cartography and Geographic Information Science 40 (5): 401-414. doi: 10.1080/15230406.2013.783450.

Nielsen, Jakob. 1992. "The Usability Engineering Life Cycle.” Computer 25 (3): 12-22. doi: 10.1109/2.121503.

Palmer, Jonathan W. 2002. "Web Site Usability, Design, and Performance Metrics." Information Systems Research 13 (2): 151-167. doi: 10.1287/isre.13.2.151.88.

Pyper, Julia. 2016. "Google's Project Sunroof Expands to 42 States and Millions More Rooftops." Greentechmedia Nerws, Software E Analytics, 20 May. Accessed June 15, 2016. http://www.greentechmedia.com/articles/read/ Googles-Project-Sunroof-Expands-to-42-States-andMillions-More-Rooftops.

Resch, Bernd, Günther Sagl, Tobias Törnros, Andreas Bachmaier, Jan-Bleicke Eggers, Sebastian Herkel, Sattaya Narmsara, and Hartmut Gündra. 2014. "GISBased Planning and Modeling for Renewable Energy: Challenges and Future Research Avenues." ISPRS International Journal of Geo-Information 3 (2): 662-92. doi: 10.3390/ijgi3020662. 
Retchless, David P., and Cynthia A. Brewer. 2015. "Guidance for Representing Uncertainty on Global Temperature Change Maps." International Journal of Climatology 36(3): 1143-1159. doi: 10.1002/joc.4408.

Rose, Gillian. 2012. Visual Methodologies: An Introduction to Researching with Visual Materials, $3^{\text {rd }}$ Edition. Los Angeles: Sage.

Roth, Robert E., Chloë Quinn, and David Hart. 2015. "The Competitive Analysis Method for Evaluating Water Level Visualization Tools." In Modern Trends in Cartography, edited by Jan Brus, Alena Vondráková, and Vít Voženílek, 241-56. Lecture Notes in Geoinformation and Cartography. Berlin \& Heidelberg: Springer. doi: 10.1007/978-3-319-07926-4_19.

Roth, Robert E. 2013. “An Empirically-Derived Taxonomy of Interaction Primitives for Interactive Cartography and Geovisualization." IEEE Transactions on Visualization and Computer Graphics 19 (12): 235665. doi: 10.1109/TVCG.2013.130.

Shneiderman, Ben. 1996. "The Eyes Have It: A Task by Data Type Taxonomy for Information Visualizations." Proceedings of the 1996 IEEE Symposium on Visual Languages, Boulder, Colorado: 336-43. doi: 10.1109/ VL.1996.545307.
Sieber, René, Christoph Schmid, and Samuel Wiesmann. 2005. "Smart Legend-Smart Atlas." Proceedings of the $22^{\text {nd }}$ International Cartographic Conference, A Coruña, Spain. http://cartesia.org/geodoc/icc2005/pdf/oral/ TEMA14/Session\%206/RENE\%20SIEBER.pdf.

Slocum, Terry A., Robert B. McMaster, Fritz C. Kessler, and Hugh H. Howard. 2009. Thematic Cartography and Geovisualization, $3^{\text {rd }}$ Edition. Geographic Information Science Series. Upper Saddle River, NJ: Prentice Hall.

Spiess, Ernst. 1970. "The Need for Efficient Base Maps in Thematic Mapping." Paper presented at the Fifth International Conference on Cartography, Stresa, Italy.

Tufte, Edward R. 1983. The Visual Display of Quantitative Information. Cheshire, CT: Graphics Press.

1990. Envisioning Information. Cheshire, CT: Graphics Press.

Webster, Jessica, Carston Beier, Reinhard Jank, Andreas Koch, and Yoshiyuki Shimoda. 2013. "Community Energy and Emissions Inventory Modelling Tools to Support Local Energy Planning (LEP).” In Case Studies and Guidelines for Energy Efficient Communities: A Guidebook on Successful Urban Energy Planning. International Energy Agency, Energy in Buildings and Communities Program, 106-29. Ottawa, ON: Natural Resources Canada. 